\title{
Transcription Factor Egr1 is Involved in High Glucose-Induced Proliferation and Fibrosis in Rat Glomerular Mesangial Cells
}

\author{
Dan Wang Mei-Ping Guan Zong-Ji Zheng Wen-Qi Li Fu-Ping Lyv Ruo-Yu Pang \\ Yao-Ming Xue
}

Department of Endocrinology and Metabolism, Nanfang Hospital, Southern Medical University, Guangzhou, Guangdong, China

\section{Key Words}

Egr1 • Diabetic nephropathy $\bullet$ TGF- $\beta 1 \cdot$ Mesangial cells $\bullet$ Extracellular matrix

\begin{abstract}
Backgroud: Diabetic nephropathy is one of the most frequent causes of end-stage renal disease and is associated with proliferation of glomerular mesangial cells (MCs) and excessive production of the extracellular matrix (ECM). Several studies have shown that early growth response factor 1 (Egr1) plays a key role in renal fibrosis by regulating the expression of genes encoding ECM components. However, whether Egr1 also contributes to diabetic nephropathy is unclear. Methods: In the present study, we compared the expression of Egr1 in kidneys from OLETF rats with spontaneous type 2 diabetes and healthy LETO rats. We also examined whether high glucose and TGF- $\beta 1$ signaling up-regulated Egr1 expression in cultured MCs, and whether Egr1 expression influenced MC proliferation and expression of ECM genes. Results: We found that higher expression of Egr1 and TGF- $\beta 1$, at both the mRNA and protein levels, the kidneys from OLETF rats vs. LETO rats. High glucose or TGF- $\beta 1$ signaling rapidly up-regulated expression of Egr1 mRNA and protein in cultured MCs. Overexpressing Egr1 in MCs by transfection with M61-Egr1 plasmid or treatment with high glucose up-regulated expression of fibronectin, type IV collagen and TGF- $\beta 1$, and promoted MC proliferation. Conversely, siRNA-mediated silencing of Egr1 expression down-regulated these genes and inhibited MC proliferation. Chromatin immunoprecipitation (ChIP) assays revealed that Egr1 bound to the TGF- $\beta 1$ promoter. Conclusion: Our results provide strong evidence that Egr1 contributes to diabetic nephropathy by enhancing MC proliferation and ECM production, in part by interacting with TGF- $\beta 1$.
\end{abstract}




\section{Cellular Physiology Cell Physiol Biochem 2015;36:2093-2107 \begin{tabular}{ll|l} 
and Biochemistry $\begin{array}{l}\text { DOI.1159/000430177 } \\
\text { Published online: July 21, 2015 }\end{array}$ & $\begin{array}{l}\text { O 2015 S. Karger AG, Basel } \\
\text { www.karger.com/cpb }\end{array}$ \\
\cline { 2 - 3 }
\end{tabular} \\ Wang et al.: Egr1 and High Glucose-Induced Fibrosis}

\section{Introduction}

Diabetic nephropathy is one of the most frequent causes of end-stage renal disease. Its causes are still unclear, which may include genetic factors, disorders of glucose/ lipid metabolism, glomerular hemodynamic changes and abnormal cytokine expression. These factors promote mesangial cell (MC) proliferation, mesangial matrix expansion and glomerular basement membrane thickening, eventually leading to glomerular sclerosis and renal tubule fibrosis.

Early growth response factor 1 (Egr1) is a zinc-finger transcription factor widely expressed in eukaryotic cells from yeast to humans [1]. It is expressed in various cell types in the kidney, including glomerular MCs, endothelial cells, renal tubular fibroblasts and epithelial cells [2]. Renal fibrosis has been linked to changes in the expression of Egr1 [3, 4]. Egr1 expression was up-regulated in a mouse model for DOCA/high salt-induced fibrotic kidney, while down-regulation of the Ankrd1-Egr1 axis may protect kidney from fibrogenesis in aged PAI-1 knockout mice. Mechanisms whereby Egr1 contributes to renal fibrosis may include promotion of MC proliferation $[5,6]$ and the synthesis of the extracellular matrix (ECM) [3], and up-regulation of transforming growth factor- $\beta$ (TGF- $\beta$ ) $[7,8]$.

These mechanisms, if they occur, may also contribute to diabetic nephropathy, and yet studies on the role of Egr1 in diabetic nephropathy have largely focused on vascular dysfunction [9], glomerular basement membrane change [10] and podocyte injury [11]. Therefore, we performed the present study to examine whether and how Egr1 contributed to renal fibrosis in diabetic nephropathy. In the in vivo experiments, we compared the expression of Egr1 and TGF- $\beta 1$ in the kidneys of rats with spontaneous type 2 diabetes (DM rats) vs. healthy rats (NDM rats). In the in vitro experiments, we examined the expression of Egr1 in rat $\mathrm{MC}$ cultures upon exposure to high glucose concentration, recombinant human TGF- $\beta 1$, or TGF- $\beta 1$ inhibitor SB-431542. In some experiments, overexpressing Egr1 or silencing Egr1 in MCs with transfection, we detected MC proliferation, biosynthesis of fibronectin and type IV collagen and TGF- $\beta 1$ expression. The results suggest that Egr1, in part by interacting with TGF- $\beta 1$, promotes high glucose-induced MC proliferation and ECM synthesis, implicating it as a key driver of pathological changes in diabetic nephropathy.

\section{Material and Methods}

\section{Animals}

OLETF rats with spontaneous type 2 diabetes (DM; $\mathrm{n}=3$ ) and healthy LETO control rats (NDM; $\mathrm{n}=3$ ) were obtained from Otsuka Pharmaceutical, Tokyo, Japan [12]. Animals were housed in individual cages and fed with standard rat chow in a specific pathogen-free facility. Rats were sacrificed at 40 weeks of age. The study protocol was approved by the local institutional review board at the authors' affiliated institution and animal studies were conducted in conformity with the established institutional and state guidelines for the care and use of laboratory animals.

\section{Renal histopathology}

The kidney tissues were obtained and fixed in $4 \%$ paraformaldehyde for $24 \mathrm{~h}$, paraffin-embedded and sectioned $(3 \mu \mathrm{m})$. Tissue sections were stained with periodic acid-Schiff (Loogene, Beijing, China) [13] and Masson's trichrome (Maiwei, Xiamen, China) [14] as previously described. Egr1 and TGF- $\beta 1$ expression was analyzed by immunohistochemistry as depicted earlier [14]. Briefly, tissue sections were incubated overnight with a rabbit anti-Egr1 polyclonal antibody (1:700 dilution; Santa Cruz Biotechnology, Santa Cruz, CA, USA) or a rabbit anti-TGF- $\beta 1$ polyclonal antibody (1:150 dilution; Santa Cruz Biotechnology), followed by horseradish peroxidase-conjugated anti-rabbit secondary antibody (DAKO, Glostrup, Denmark). Sections were then counterstained with hematoxylin. All sections were analyzed using an Olympus B $\times 40$ upright light microscope (Olympus, Tokyo, Japan).

\section{KARGER}




\section{Cellular Physiology Cell Physiol Biochem 2015;36:2093-2107

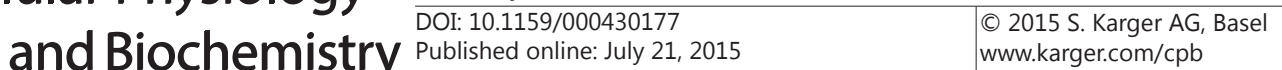

\section{Cell culture and treatment}

Rat glomerular MCs (HBZY-1) were cultured at $37{ }^{\circ} \mathrm{C}$ in a $5 \% \mathrm{CO}_{2}$ humidified incubator in complete Dulbecco's modified Eagle's low glucose medium (DMEM, low glucose) containing 10\% fetal bovine serum (FBS). The medium was changed every 2 days. Depending on the experiment, cultures were treated with high glucose (30 mmol/L; Sigma, Saint Louis, MO, USA), mannitol (24.5 mmol/L; Fuchen, Tianjin, China), recombinant human TGF- $\beta 1$ (20 ng/mL; Gibco, New York, NY, USA) or TGF- $\beta 1$ inhibitor SB-431542 (10 $\mu \mathrm{mol} / \mathrm{L}$; Santa Cruz Biotechnology).

\section{Cell transfection}

SiRNA transfection. MCs were seeded in 12-well flat-bottom plates at approximately 50\% confluence and transfected with small interfering RNA (siRNA) targeting Egr1 (siEgr1, 40 pmol/L; Yini, Shanghai, China) or a scrambled RNA (40 pmol/L; Yini) for $4 \mathrm{~h}$ using HilyMax liposome transfection reagent (DojinDo, Kumamoto, Japan) according to the manufacturer's instructions. After removal of transfection mixtures, cells were cultured for $24 \mathrm{~h}$ in medium containing low glucose $(5.5 \mathrm{mmol} / \mathrm{L})$ or high glucose $(30 \mathrm{mmol} / \mathrm{L})$ prior to detection of Egr1 and potential downstream targets.

Plasmid and siRNA co-transfection. In some experiments, MCs were cultured at $80 \%$ confluence in 12-well plates and transfected with a plasmid expressing Egr1 (M61-Egr1, $2 \mu \mathrm{g}$; Genecopoeia, Guangzhou, China), empty vector (M61, $2 \mu \mathrm{g}$; Genecopoeia), or both M61-Egr1 (2 $\mu \mathrm{g})$ and siEgr1 (40 pmol/L) cotransfection using HilyMax reagent according to the manufacturer's instructions. After $24 \mathrm{~h}$, cells were collected and measured.

\section{Real time RT-PCR}

Renal tissues and MCs were lysed in Trigol (Dingguo, Beijing, China) and total cellular RNA was extracted. RNA quality was determined using the NanoDrop ND-1000 spectrophotometer (Thermo Fisher Scientific, MA, USA). The RNA samples were reverse-transcribed using $M-M L V$ reverse transcriptase (Invitrogen, Carlsbad, CA, USA). Real-time quantitative PCR was carried out in a Roche 480 thermal cycler using $40 \mathrm{ng}$ of cDNA, SYBR Select Master Mix (Invitrogen) and appropriate primers (Invitrogen) whose sequences are shown in Table 1 . The following cycling conditions were used: $50{ }^{\circ} \mathrm{C}$ for 2 min, then $95^{\circ} \mathrm{C}$ for $2 \mathrm{~min}$, and finally 40 cycles of $95^{\circ} \mathrm{C}$ for $15 \mathrm{sec}$ and $60^{\circ} \mathrm{C}$ for $1 \mathrm{~min}$. The relative expression of each gene was calculated using the comparative $2^{-\Delta \Delta \mathrm{ct}}$ method, using $\beta$-actin as the reference.

\section{Western blotting assays}

Total protein was extracted from renal tissues and MCs using RIPA Lysis Buffer (Beyotime Institute of Biotechnology, Shanghai, China). Protein concentration was estimated using a BCA assay (Dingguo, Beijing, China). Equal amounts of proteins were fractionated by $10 \%$ or $15 \%$ SDS-PAGE (Bio-Rad Laboratories, Hercules, CA, USA) and electro-transferred to polyvinylidene fluoride membranes (Merck Millipore, MA, USA). Membranes were blocked with Tris-buffered saline containing 0.1\% Tween-20 (TBST) and 5\%

Table 1. Sequences of primers for quantitative RT-PCR in this study

\begin{tabular}{llc}
\hline Gene & Primers & Product size (bp) \\
\hline \multirow{2}{*}{ Egr1 } & Sense: 5'-CCAGTGCCCACCTCTTACTC-3' & 144 \\
\multirow{2}{*}{ TGF- $\beta 1$} & Antisense: 5'-TGCAGACTGGAAGGTGCTG-3' & \\
& Sense: 5'-CTTTGTACAACAGCACCCGC-3' & 94 \\
Fibronectin & Antisense: 5'-CGGGTGACTTCTTTGGCGTA-3' & \\
\multirow{2}{*}{ Type IV collagen } & Sense: 5'-TGGAGAGACAGGAGGAAATAGC-3' & 122 \\
& Antisense: 5'-CAGTGACAGCATACAGGGTGAT-3' & \\
$\beta$-actin & Sense: 5'-GCGAGTACAACCTTCTTGCAG-3' & 151 \\
& Antisense: 5'-GCCTTGCACATGCCGGA-3' & 115 \\
\hline
\end{tabular}




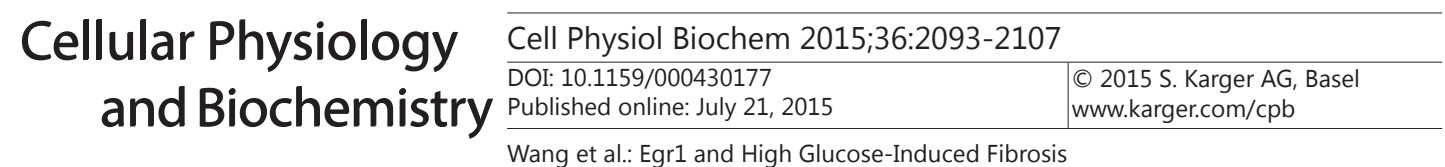

Table 2. Primer sequences for PCR analysis of ChIP-enriched DNA in this study

\begin{tabular}{ll}
\hline Gene region (initial nt) & Primer sequence \\
\hline TGF- $\beta 1(1)(-1273)$ & Sense: 5'-GTGCACCTTGGTATCGGTCT-3' \\
& Antisense: 5'-CCGGTAATTCAGTGGAGCAT-3' \\
TGF- $\beta 1(2)(-448)$ & Sense: 5'-TTTGAGACTTTTCCGCTGCT-3' \\
& Antisense: 5'-GCTTTGGGGTGAAGTCTTTG-3' \\
PDGF-B (-737) & Sense: 5'-CTCTCGGAGACCCTGTCAAG-3' \\
& Antisense: 5'-GAGAAGTTGCCACCCTTCAG-3' \\
\hline
\end{tabular}

skim milk, then incubated overnight with a primary antibody against Egr1 (1:500 dilution; Santa Cruz Biotechnology), TGF- $\beta 1$ (1:100 dilution; Santa Cruz Biotechnology), or fibronectin (1:500 dilution; Abcam, MA, USA). Membranes were then incubated with an IRDye 800CW-conjugated secondary antibody (1:15000 dilution; LI-COR Biosciences, NE, USA) for $1 \mathrm{~h}$. Fluorescence signal was visualized using the Odyssey infrared imaging system (LI-COR) and quantified using Quantity One 4.4.0.

Enzyme-linked immunosorbent assay (ELISA)

Culture medium was centrifuged at $2000 \mathrm{~g}$ for $20 \mathrm{~min}$, and the supernatants were assayed for fibronectin and type IV collagen using commercial ELISA kits (Jianglai, Shanghai, China). Absorbance was read at $450 \mathrm{~nm}$ using an ELx800 microplate reader (Bio-tek, VT, USA).

Cell proliferation (CCK-8) assay

MCs were seeded in 96-well flat-bottom plates at a density of $4 \times 10^{3}$ cells/well, and cultured at approximately 50\% confluence in 1\% FBS DMEM low glucose medium for $24 \mathrm{~h}$ for synchronization. Thereafter, cells were transfected for $4 \mathrm{~h}$ with siEgr1 or a scrambled control, and then treated with high glucose $(30 \mathrm{mmol} / \mathrm{L})$ or low glucose $(5.5 \mathrm{mmol} / \mathrm{L})$. Cultures were incubated for 12,24 and $48 \mathrm{~h}$, and $10 \mu \mathrm{L}$ of CCK-8 solution (DojinDo) was added to each well. Cultures were incubated a further $1 \mathrm{~h}$ at $37^{\circ} \mathrm{C}$, and then the absorbance was read at $450 \mathrm{~nm}$ using an ELx800 microplate reader (Bio-tek).

\section{Chromatin immunoprecipitation (ChIP)}

Chromatin immunoprecipitation was performed using the EZ-ChIP Kit (Millipore). Briefly, MCs were cross-linked, chromatin was isolated, and genomic DNA was sheared by sonication into fragments of 200$600 \mathrm{bp}$. Cross-linked protein-DNA was immunoprecipitated overnight with $1 \mathrm{~g}$ of anti-Egr1 antibody (Santa Cruz Biotechnology) or control IgG. The immunoprecipitated ChIP product was washed, de-cross-linked, treated with proteinase $\mathrm{K}$, and eluted to obtain ChIP-enriched DNA. PCR contained the ChIP-enriched DNA, primers (Sangon Biotech, Shanghai, China) to amplify Egr1 binding sites in the TGF- $\beta 1$ promoter or a binding site in the promoter of the gene encoding platelet-derived growth factor (PDGF)-B [15] as a positive control (Table 2), and the SYBR Premix Ex Taq II kit (Takara, Shiga, Japan). PCR products were analyzed on a $2 \%$ agarose gel.

\section{Statistical analysis}

Data were expressed as mean \pm SD. Two-tailed Student's $t$ test was used for pairwise comparisons of independent groups. One-way ANOVA was used to compare three or more independent groups, and Dunnett test or the least significant difference (LSD) test was used for multiple comparisons. Statistical calculations were performed using SPSS 13.0 (IBM, IL, USA), with $p<0.05$ considered significant.

\section{Results}

In vivo correlation of renal fibrosis in diabetic nephropathy and elevated expression of Egr1 and TGF- $\beta 1$

We compared the levels of Egr1 and TGF- $\beta 1$ gene and protein expression in renal tissue from DM rats and NDM rats. We also examined tissues from both groups to search for 


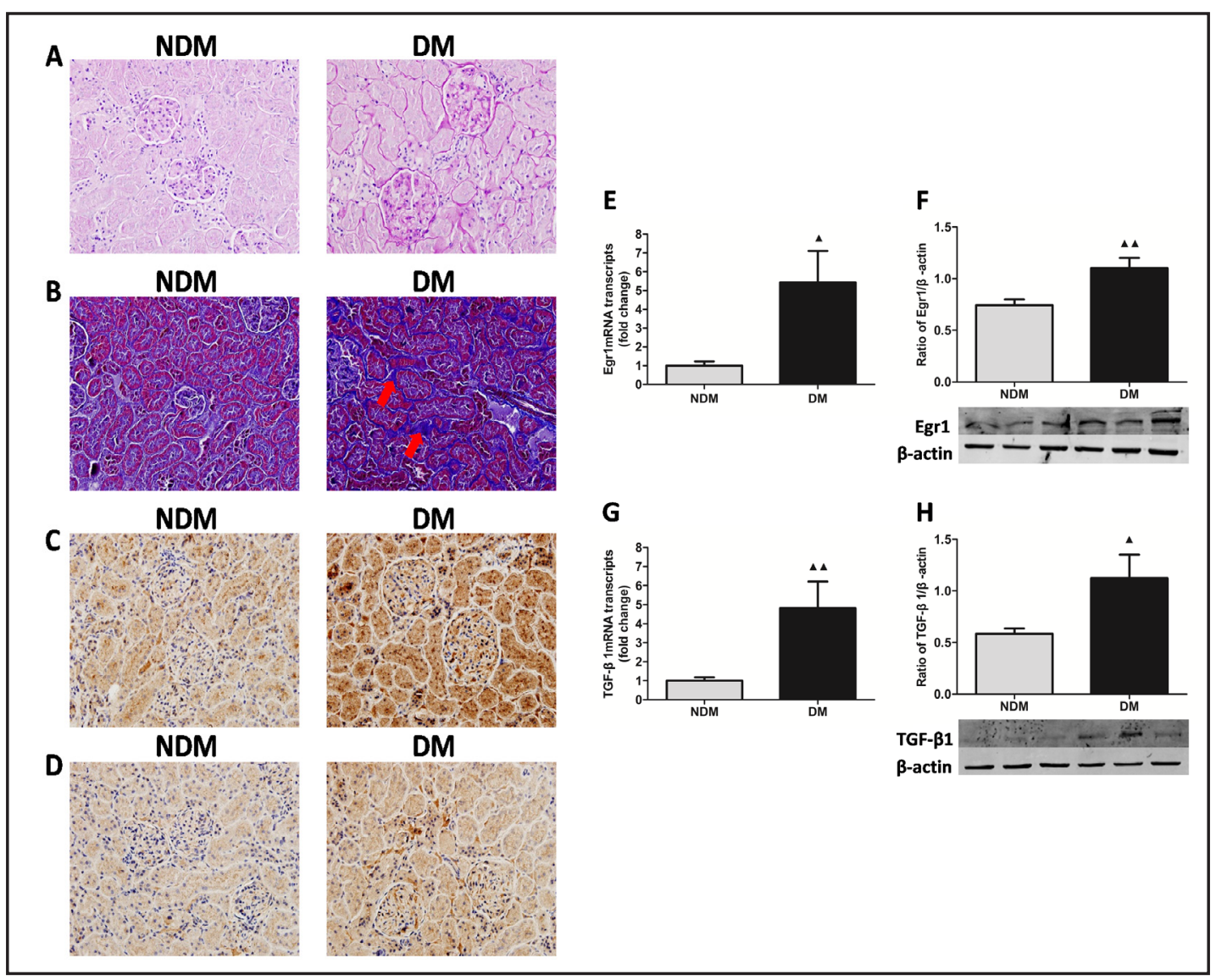

Fig. 1. Histopathology and expression of Egr1 and TGF- $\beta 1$ in the kidneys of OLETF rats with spontaneous type 2 diabetes and non-diabetic LETO rats. Kidney sections from 40-week-old diabetic OLETF rats (DM, $\mathrm{n}=3$ ) and control LETO rats (NDM, n=3) are stained with (A) periodic acid-Schiff ( darker purple color indicates positive staining) or (B) Masson-Trichrome (blue staining indicates positive staining; red arrows indicate renal tubular interstitial collagen deposition), and analyzed by immunohistochemistry using antibodies against (C) Egr1 or (D) TGF- $\beta 1$. Magnification, $\times 400$. Egr1 expression in total kidney lysates from both groups of rats is analyzed by (E) quantitative RT-PCR and (F) Western blotting assays, as is TGF- $\beta 1$ expression $(G, H)$. Values are mean $\pm \mathrm{SD} ; \boldsymbol{\Delta} P<0.05, \wedge \boldsymbol{\Delta} P<0.01$.

glomerular and renal tubular morphological changes. We examined renal tissue in rats aged 40 weeks as previous work showed that fasting blood glucose was significantly higher in DM rats than in NDM controls at this age [12].

PAS staining showed that the glomerular capillary basement membrane was thicker and the mesangial matrix was enlarged in DM rats compared to the control rats (Fig. 1A). Masson staining revealed more extensive tubular interstitial collagen deposition in DM rats than in control rats (Fig. 1B).

Immunohistochemistry showed much more abundant Egr1 in the kidneys of DM rats than in control rats (Fig. 1C). The quantitative RT-PCR assays demonstrated 5 -fold higher Egr1 mRNA transcript levels in the kidney of DM rats than the control rats $(p<0.05$, Fig. 1E). Consistently, Western blotting assays also showed a much higher level of Egr1 protein in DM rats $(p<0.01$, Fig. $1 \mathrm{~F})$.

Furthermore, immunohistochemistry (Fig. 1D) and quantitative RT-PCR assays (Fig. $1 \mathrm{G})$ revealed that TGF- $\beta 1$ expression was up-regulated in the kidney of DM rats compared to the NDM rats $(p<0.01)$, which was further confirmed by Western blotting assays $(p<0.05$, Fig. 1H). 
A

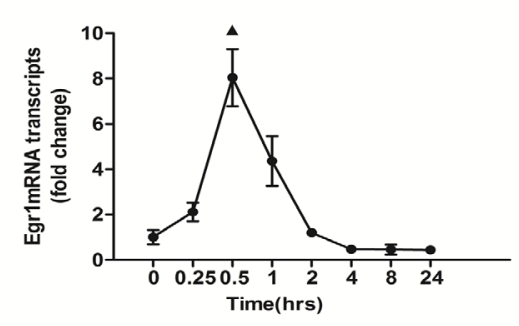

C

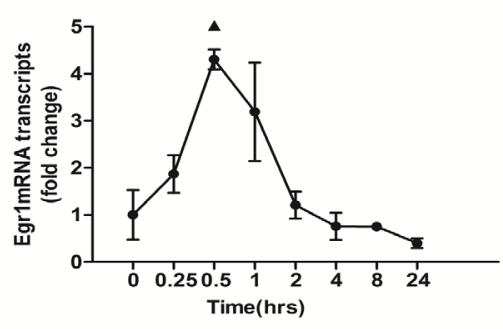

E

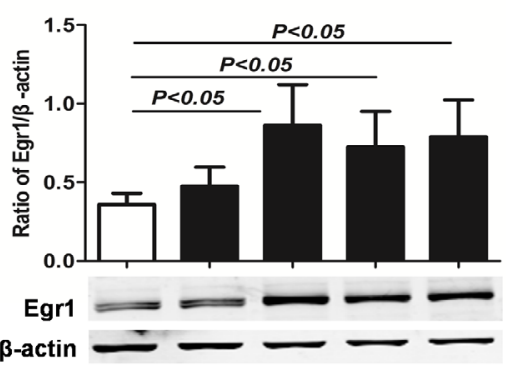

Glucose(5.5mM)

Glucose(30mM)

Mannitol(24.5mM)

TGF-ק1(20ng/mL)
B

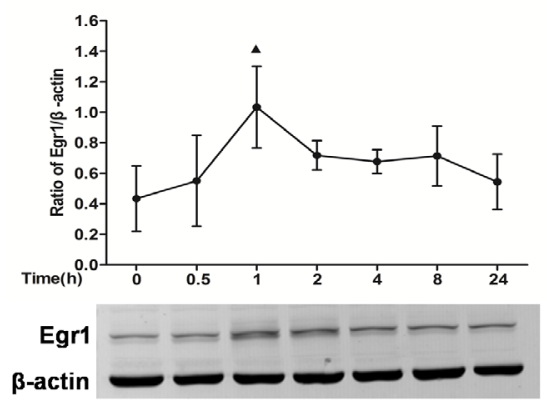

D

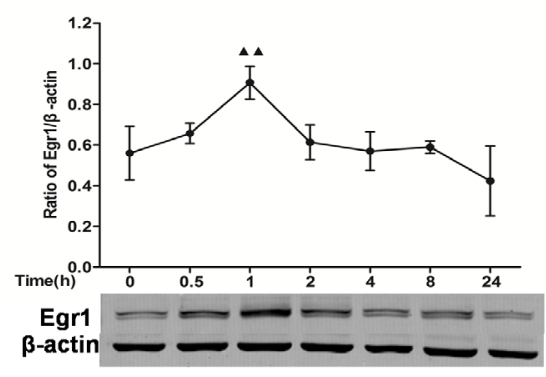

$\mathbf{F}$

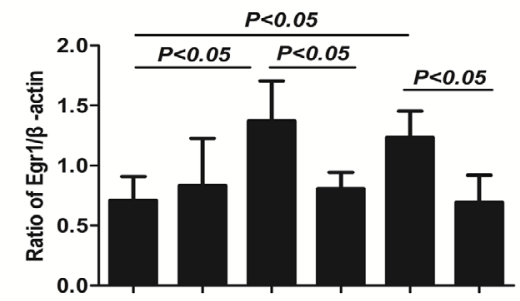

Egr1 $-\div$

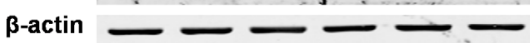

$\operatorname{Glucose}(5.5 \mathrm{mM})+\quad+\quad+\quad+\quad-$

Glucose $(30 \mathrm{mM}) \quad$ - $\quad$ - $\quad$ - $\quad+\quad+\quad+$

TGF- $\beta 1(20 \mathrm{ng} / \mathrm{mL}) \quad-\quad-\quad+\quad+\quad+\quad+$

SB-431542(10uM) $\quad+\quad+\quad+\quad+\quad+$

Fig. 2. Egr1 expression in rat glomerular mesangial cells (HBZY-1). (A, C) The Egr1 mRNA transcript levels are determined at the indicated time points by quantitative RT-PCR in mesangial cells (MCs) treated with (A) high glucose (30 mmol/L) or (C) TGF- $\beta 1(20 \mathrm{ng} / \mathrm{mL})$. The results are expressed as fold change over baseline $(0 \mathrm{~h})$. (B, D) Levels of Egr1 protein are assessed at the indicated time points by Western blotting assays in MCs treated with (B) high glucose or (D) TGF- $\beta 1$. Results are expressed as the ratio of Egr1 to $\beta$-actin relative to the corresponding ratio at baseline $(0 \mathrm{~h})$. Values are mean \pm SD of three independent measurements. $\mathbf{\Delta} P<0.05, \Delta \mathbf{\Delta} P<0.01$. (E) Levels of Egr1 protein are assessed by Western blotting assays in MCs treated for $1 \mathrm{~h}$ with high glucose or low glucose $(5.5 \mathrm{mmol} / \mathrm{L})$ in the presence of TGF- $\beta 1$. MCs treated with mannitol (24.5 mmol/L) serve as an osmotic control. (F) Levels of Egr1 are measured by Western blotting assays in MCs treated with the TGF- $\beta 1$ inhibitor SB-431542 for $4 \mathrm{~h}$, then exposed for $1 \mathrm{~h}$ to high or low glucose in the presence of TGF- $\beta 1$. Results are expressed as the ratio of Egr1 to $\beta$-actin from at least three independent experiments. Values are mean \pm SD. 


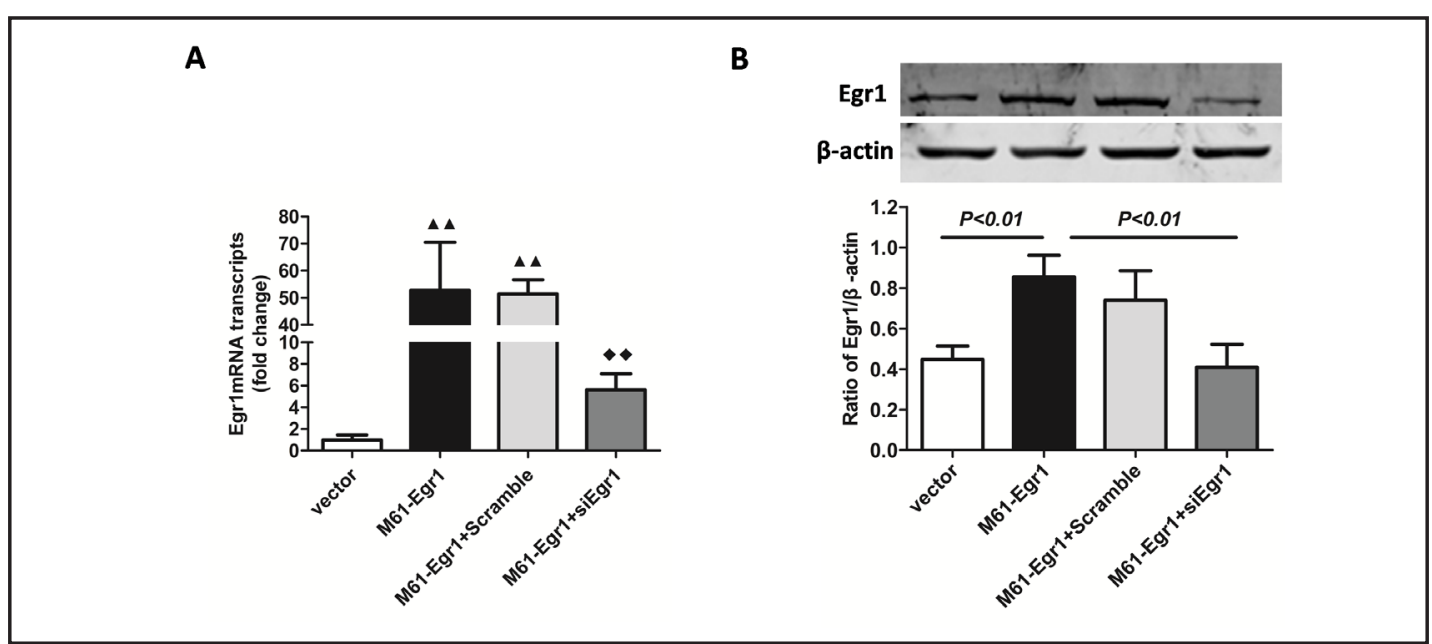

Fig. 3. Egr1 expression in MCs transiently transfected with a plasmid overexpressing Egr1. Cells are transfected using empty vector (M61), plasmid encoding Egr1 (M61-Egr1), or the combination of both M61-Egr1 and either a small interfering RNA against Egr1 (siEgr1) or a scrambled control RNA. All transfected cultures were incubated in normal medium for $24 \mathrm{~h}$ before experiments. (A) Levels of Egr1 mRNA are assessed using quantitative RT-PCR, and (B) levels of protein are assessed by Western blotting assays. Values are mean \pm SD of three measurements. ${ }^{\boldsymbol{\Delta}} P<0.01$ vs. the empty vector group; ${ }^{\star} P<0.01$ vs. the M61-Egr1 group.

Egr1 expression induced by high glucose or TGF- $\beta 1$ in MCs

Since chronic hyperglycemia in diabetics is thought to contribute to diabetic nephropathy, we tested whether exposing MC cultures to high glucose up-regulated Egr1 expression, which would provide indirect evidence that Egr1 contributes to the disease process. We chose MCs as the model because they can synthesize and release ECM components, including fibronectin, type IV collagen, perlecan, and laminin [16]. MC proliferation, ECM accumulation and glomerular basement membrane thickening play important roles in the pathogenesis of diabetic nephropathy.

MCs treated with high glucose $(30 \mathrm{mmol} / \mathrm{L})$ for $24 \mathrm{~h}$ showed time-dependent upregulation of Egr1 expression. Egr1 mRNA transcript levels peaked at $30 \mathrm{~min}$ (8-fold higher than at baseline; $p<0.05$ ), which returned towards the baseline at 2 hours (Fig. $2 \mathrm{~A}$ ). Western blotting assays of Egr1 protein revealed similar temporal patterns (Fig. 2B). Upregulation of Egr1 upon treatment with recombinant TGF- $\beta 1(20 \mathrm{ng} / \mathrm{mL})$, at both the mRNA and protein levels, was similar to that induced by high glucose (Fig. $2 \mathrm{C}$ and D).

To gain a more complete picture of the factors that may affect Egr1 expression in the context of diabetic nephropathy, we tested whether high glucose and TGF- $\beta 1$ can synergistically affect Egr1 expression and whether hyperosmotic stress can also influence its expression. We treated MC cultures for $1 \mathrm{~h}$ with mannitol $(24.5 \mathrm{mmol} / \mathrm{L})$, high glucose (30 mmol/L), and/or TGF- $\beta 1(20 \mathrm{ng} / \mathrm{mL})$. We found, as before, that high glucose or TGF- $\beta 1$ alone significantly up-regulated Egr1 protein expression $(p<0.05$, Fig. $2 \mathrm{E})$. Treating cultures with both high glucose and TGF- $\beta 1$ together also up-regulated Egr1, but to a similar extent as either treatment alone. Mannitol, for its part, did not significantly affect Egr1 expression ( $p>$ 0.05). TGF- $\beta 1$ inhibitor SB-431542 (10 $\mu \mathrm{mol} / \mathrm{L})$ prevented the up-regulation of Egr1 protein induced by TGF- $\beta 1$ or TGF- $\beta 1$ plus high glucose in cultured MCs (Fig. 2 F).

Role of Egr1 in regulating expression of fibronectin, type IV collagen and TGF- $\beta 1$ under normal conditions in MC cultures

Diabetic nephropathy is also associated with elevated type IV collagen in the urine [17] and increased secretion of fibronectin [18], but whether Egr1 up-regulates the expression of fibronectin and type IV collagen in MCs has not been directly demonstrated. Transfection of cultured MCs with a plasmid encoding Egr1 (M61-Egr1) increased the expression of Egr1 


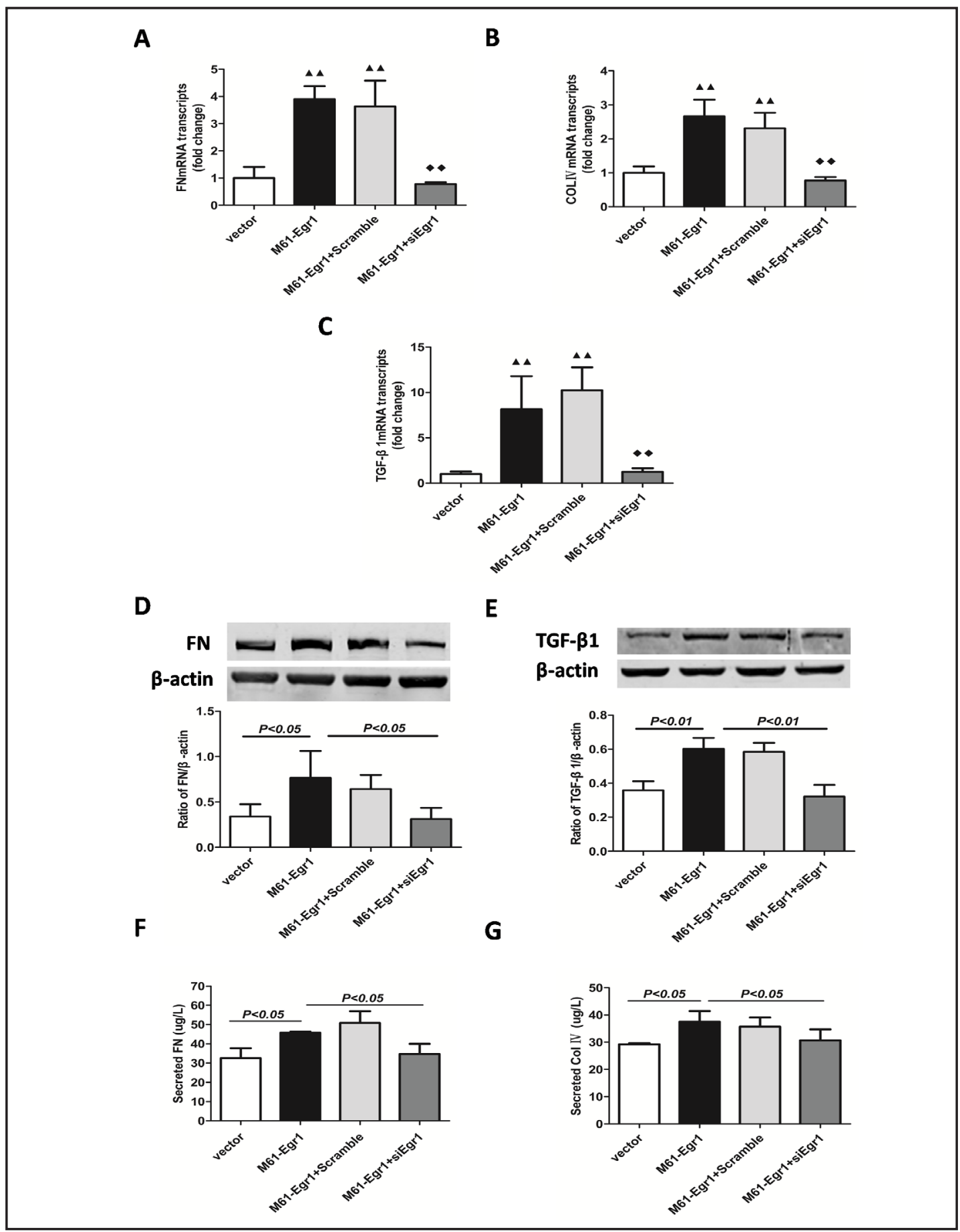

Fig. 4. Induction of profibrotic genes in MCs transiently transfected with a plasmid overexpressing Egr1. Cells are transfected with empty vector (M61), plasmid encoding Egr1 (M61-Egr1), or the combination of both M61-Egr1 and either a short interfering RNA against Egr1 (siEgr1) or a scrambled control RNA. All transfected cultures are incubated in normal medium for $24 \mathrm{~h}$ before experiments. Levels of mRNA transcripts from the genes encoding (A) fibronectin (FN), (B) type IV collagen (COL IV), and (C) TGF- $\beta 1$ are measured using quantitative RT-PCR. Results are expressed as fold change compared with the empty vector group. ${ }^{\wedge} P<0.01$ vs. the empty vector group; ${ }^{\star} P<0.01$ vs. M61-Egr1 group. Levels of (D) fibronectin protein and (E) TGF- $\beta 1$ protein are analyzed using Western blotting assays. Results are expressed as the ratio of fibronectin or TGF- $\beta 1$ to $\beta$-actin. ELISA is used to assay the levels of (F) fibronectin and (G) type IV collagen secreted into the culture medium. All values are mean \pm SD of three measurements. 
A

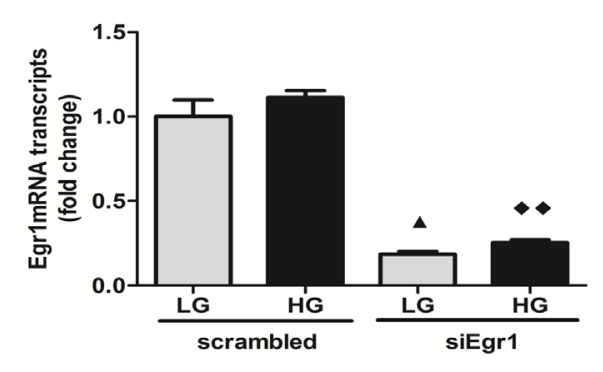

B

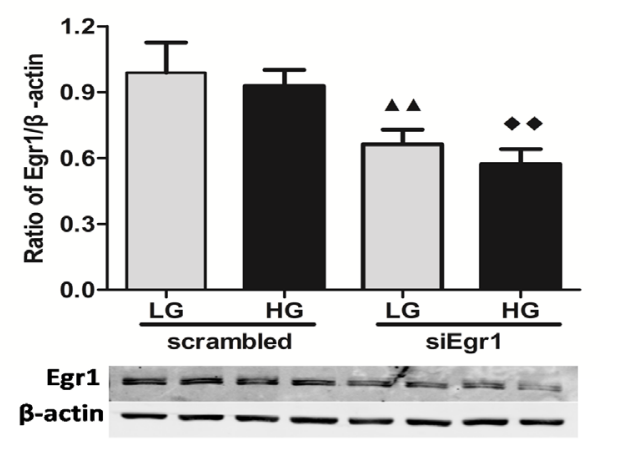

Fig. 5. Egr1 expression in MCs transiently transfected with siEgr1. Cells were either silenced with siEgr1 or treated with a scrambled control RNA and then exposed for $24 \mathrm{~h}$ to low glucose (LG, $5.5 \mathrm{mmol} / \mathrm{L}$ ) or high glucose (HG, $30 \mathrm{mmol} / \mathrm{L}$ ). (A) Levels of Egr1 mRNA transcripts were measured using quantitative RT-PCR. Values are mean \pm SD of three measurements. (B) Levels of Egr1 protein are measured using Western blotting assays. Values are mean \pm SD of four measurements. ${ }^{\Delta} P<0.05$ and ${ }^{\boldsymbol{\Delta}} \boldsymbol{\Delta} P<0.01$ vs. the scramble + LG group; $\bullet P<0.01$ vs. the scramble + HG group.

( $p<0.01$ vs. empty vector; Fig.3A and B). The expression of fibronectin, type IV collagen and TGF- $\beta 1$ mRNA was increased by 4,3 and 8 -folds, respectively ( $p<0.01$ vs. empty vector; Fig. $4 \mathrm{~A}-\mathrm{C})$.

Co-transfecting MC cultures with siEgr1 attenuated the effects of M61-Egr1, as reflected by lower expression of Egr1 at both the mRNA and protein levels ( $p<0.01$, Fig. $3 \mathrm{~A}$ and $\mathrm{B})$, as well as decreased fibronectin, type IV collagen and TGF- $\beta 1$ mRNA $(80 \%, 71 \%$ and $85 \%$ lower, respectively) relative to M61-Egr1 transfection alone ( $p<0.01$, Fig. 4 A-C). Similar results with fibronectin and TGF- $\beta 1$ were observed at the protein level based on the results of Western blotting assays (Fig. 4D and E).

Similar to our quantitative RT-PCR results, transfection of cultured MCs with M61-Egr1 increased the secretion of fibronectin and type IV collagen (into the culture medium); cotransfection with siEgr1 decreased their secretion in comparison with M61-Egr1 transfection alone $(p<0.05$, Fig. 4 F and $\mathrm{G})$.

Role of Egr1 in promoting MC proliferation, ECM secretion and TGF- $\beta 1$ synthesis under high-glucose conditions

Transfection with the scrambled sequence did not affect Egr1 expression in both high and low glucose conditions, consistent with our experiments above showing time-dependent up-regulation of Egr1 expression by high glucose. Transfection with siEgr1 was evidently effective in both glucose conditions, as reflected by decreased Egr1 expression at both the mRNA and protein levels ( $p<0.05$ or $p<0.01$ vs. the scrambled sequence, Fig. 5A and B).

In cultured MCs transfected with scrambled RNA, expression of fibronectin, type IV collagen and TGF- $\beta 1$ was significantly higher under high-glucose conditions than under low-glucose conditions. Transfection with siEgr1 decreased the expression of fibronectin, type IV collagen and TGF- $\beta 1$ in cultured MCs under the high-glucose condition (relative to scrambled sequence; Fig. 6A-E). Similar results were obtained for secreted fibronectin and type IV collagen as measured by ELISA, though differences were not significant between siEgr1-transfected and scrambled RNA-transfected cells or between cells exposed to low or high glucose (Fig. 6F and G).

Since high glucose [18] as well as Egr1 $[5,6]$ can promote MC proliferation, we hypothesized that Egr1 mediates high glucose-induced MC proliferation. To test this idea, we examined the effects of siEgr1 transfection on MC proliferation under high glucose conditions using the CCK-8 assays. 
A

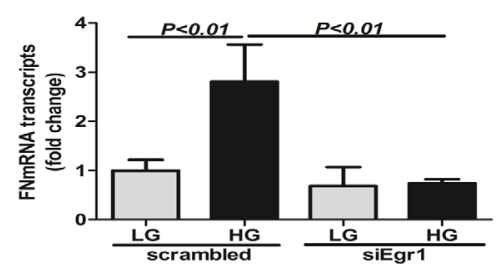

B

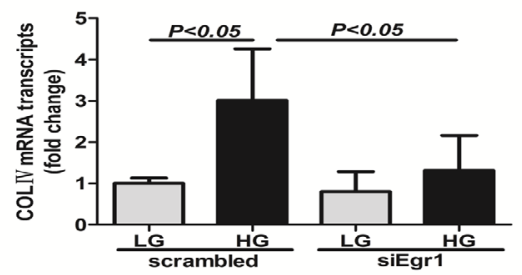

C

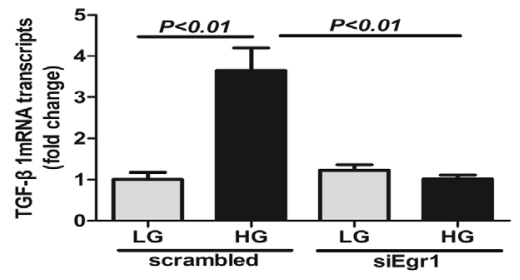

D
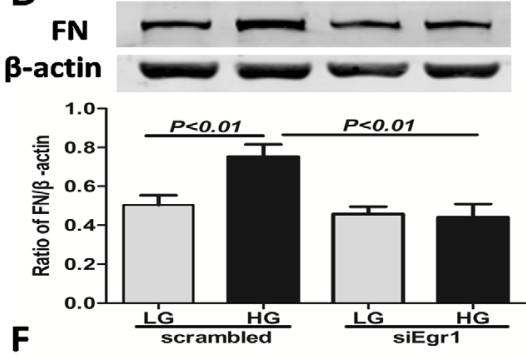

$\mathbf{F}$

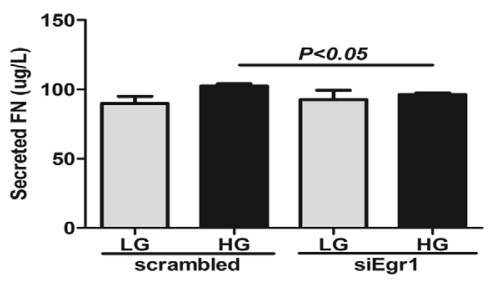

E

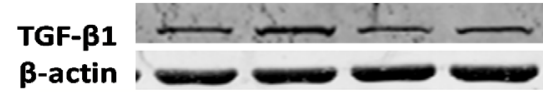

G
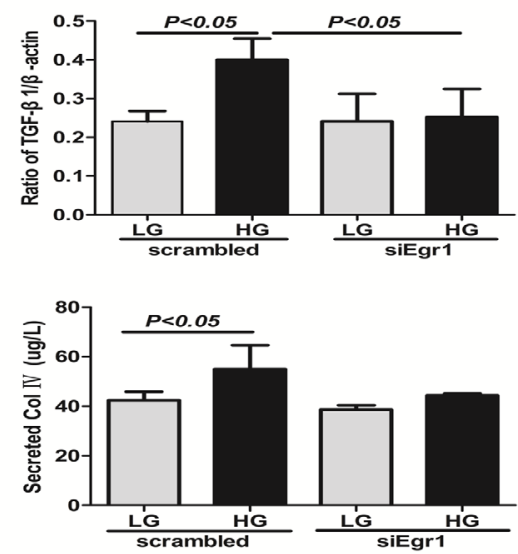

H

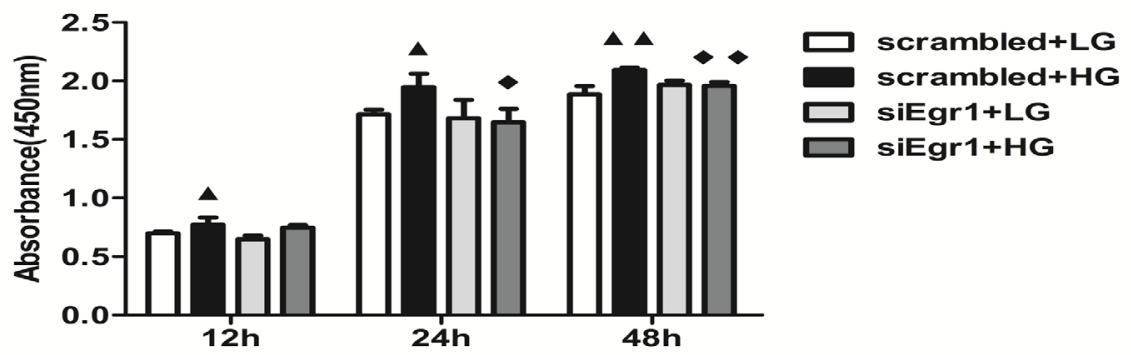

Fig. 6. MC proliferation and expression of profibrotic genes related to Egr1 in MCs transfected with siEgr1. Cells are either silenced with siEgr1 or treated with a scrambled control RNA and then exposed for $24 \mathrm{~h}$ to low glucose (LG, $5.5 \mathrm{mmol} / \mathrm{L}$ ) or high glucose ( $\mathrm{HG}, 30 \mathrm{mmol} / \mathrm{L}$ ). Levels of transcripts of genes encoding (A) fibronectin (FN), (B) type IV collagen (COL IV) or (C) TGF- $\beta 1$ are measured using quantitative RT-PCR. Results are expressed as fold change relative to cells transfected with scrambled RNA and exposed to low glucose. Levels of (D) fibronectin protein and (E) TGF- $\beta 1$ protein are measured by Western blotting assays. Results are expressed as the ratio of fibronectin or TGF- $\beta 1$ to $\beta$-actin. ELISA is used to assay the levels of (F) fibronectin and (G) type IV collagen in the culture medium. All values are mean \pm SD of three measurements. (H) CCK-8 assay to analyze effects of Egr1 on high glucose-induced MC proliferation. Cells are either silenced with siEgr1 or treated with a scrambled control RNA and then exposed to high or low glucose for 12, 24 or $48 \mathrm{~h}$. Values are mean \pm SD of three measurements. $\boldsymbol{\Delta}^{\mathbf{\Delta}} P<0.05$ and $\boldsymbol{\Delta}^{\mathbf{\Delta}} P<0.01$ vs. the scramble + LG group; ${ }^{\bullet} P$ $<0.05$ and $\bullet P<0.01$ vs. the scramble + HG group. 
Fig. 7. CHIP to probe Egr1 binding to the TGF- $\beta 1$ promoter. ChIP is performed using anti-Egr1 antibody (top) or a negative control IgG antibody (middle) in MCs treated for $1 \mathrm{~h}$ with high or low glucose. Immunoprecipitated DNA is subjected to PCR using specific TGF- $\beta 1$ primers that include the Egr1 binding sites. Amplicons are represented in the figure.

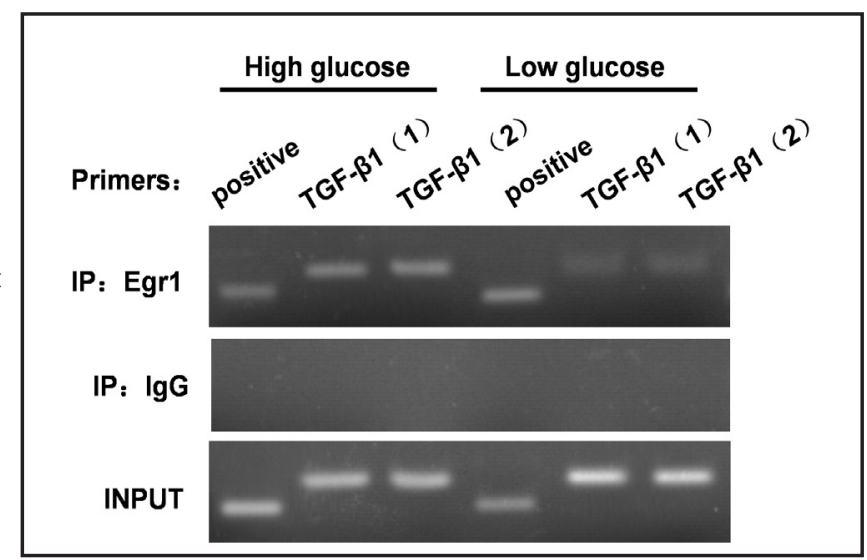

Upon transfection with scrambled RNA, the proliferation of MCs was higher under high glucose conditions than under low glucose conditions by $11 \%$ at $12 \mathrm{~h}(p<0.05), 13.5 \%$ at 24 $\mathrm{h}(p<0.05)$ and $11 \%$ at $48 \mathrm{~h}(p<0.01)$. Transfection with siEgr1 inhibited the proliferation of MCs, relative to scrambled RNA, under high glucose condition by $3.6 \%$ at $12 \mathrm{~h}(p>0.05)$, $15 \%$ at $24 \mathrm{~h}(p<0.05)$, and $6.2 \%$ at $48 \mathrm{~h}(p<0.01$, Fig. $6 \mathrm{H})$.

Next, MC cultures were incubated in low glucose $(5.5 \mathrm{mmol} / \mathrm{L})$ or high glucose $(30 \mathrm{mmol} / \mathrm{L})$ for $1 \mathrm{~h}$, and then the ChIP assay was performed. High glucose increased Egr1 binding to the TGF- $\beta 1$ promoter, but not to the PDGF-B promoter (Fig. 7, top). No enrichment was observed since control IgG did not immunoprecipitate chromatin (Fig. 7, middle).

\section{Discussion}

As the incidence of diabetes rises, so does the incidence of one of its most severe complications, diabetic nephropathy. This is the second most frequent cause of end-stage kidney disease, highlighting the need for better prevention and management. The nuclear transcription factor Egr 1 is associated with renal fibrosis [3, 4]. In addition, Egr1 is associated with diabetic nephropathy [9-11]. The present study confirms and extends previous work by providing strong evidence that Egr1 contributes to diabetic nephropathy by promoting high glucose-induced MC proliferation and ECM synthesis, partially via the TGF- $\beta 1$ signaling pathway.

Diabetes and a high glucose environment rapidly up-regulate Egr1 expression in glomerular endothelial cells [19], human embryonic kidney cells 293 [10], pancreatic beta cells [20], aortic endothelial cells [21] and renal cortical fibroblasts [22]. We extend that literature to show a similarly rapid increase in MCs: during stimulation with $30 \mathrm{mmol} / \mathrm{L}$ glucose, the mRNA transcript levels of Egr1 peaked after $30 \mathrm{~min}$, while protein expression peaked at $1 \mathrm{~h}$, and these levels returned to baseline at $24 \mathrm{~h}$. Together, our results and those of previous studies point to Egr1 as an early gene. We confirmed these in vitro results in kidney tissue from 40-week-old DM rats. This is consistent with a report by Gil et al. [10] that the level of Egr1 mRNA was noticeably higher in mice in which diabetes had been induced with STZ 10 weeks prior than in non-diabetic control mice.

MC proliferation is a key pathological feature in a number of common human renal diseases including glomerulonephritis and diabetic nephropathy. A number of factors have been shown to play a role in controlling MC proliferation, including signaling molecules (e.g. platelet-derived growth factor, Ras and $\mathrm{Ca}^{2+}$ ), cell cycle proteins (e.g. cyclin D1) and transcription factors (E2F) [23]. Several in vitro and in vivo studies have shown that Egr1 stimulates MC proliferation in the context of glomerulonephritis $[5,6,24]$. We extend that literature by providing evidence for the same effect in MCs under high-glucose conditions, which mimics to some extent the context of diabetic nephropathy. The viability of MCs transfected with a control (scrambled) RNA and incubated under high-glucose conditions 


\section{Cellular Physiology Cell Physiol Biochem 2015;36:2093-2107 \begin{tabular}{l|l|l} 
DOI: 10.1159/000430177 & $\begin{array}{l}\text { O 2015 S. Karger AG, Basel } \\
\text { www.karger.com/cpb }\end{array}$ \\
\hline
\end{tabular} \\ Wang et al.: Egr1 and High Glucose-Induced Fibrosis}

was significantly higher than that of MCs transfected with the same scrambled RNA and incubated under low-glucose conditions, at all three time points tested $(12,24$ and $48 \mathrm{~h}$ ). When MCs were transfected with siEgr1 and incubated under high-glucose conditions, viability was lower than that of MCs transfected with the scrambled RNA. This suggests that Egr1 regulates high glucose-induced proliferation of MCs. Previous studies suggest that the net effect of Egr1 on proliferation can be complex. On one hand, treating umbilical vein endothelial cells, skin microvascular endothelial cells or human epidermal cells with growth factors, cytokines or ionizing radiation activates Egr1, which induces the cells to enter G1 phase from G0. The result is cell proliferation that may play an important role in cell growth, differentiation and damage repair $[25,26]$. On the other hand, Egr1 can also promote apoptosis by up-regulating p53 expression, by combining with the transcription factor c-Jun and by activating the PTEN gene [27-29]. Further studies are needed to understand whether and how these potentially opposing pathways occur or interact in diabetic nephropathy.

Several studies have shown that in various injury and disease contexts, Egr1 regulates expression of several genes related to ECM synthesis and degradation. Egr1 competes with specificity protein 1 (Sp1) to bind to the GC-rich motifs in the promoter of the gene encoding matrix metalloproteinase-14 (MMP-14), up-regulating its expression [30]. Egr1 also upregulates the expression of plasminogen activator inhibitor-1 (PAI-1) and fibronectin by acting through TGF- $\beta$ [31]. Egr1 also promotes collagen synthesis, angiogenesis, and wound healing at dermal wounds in mice and rats [32]. The present work extends this literature by showing that, in the context of MCs under high-glucose conditions that mimic diabetic nephropathy, Egr1 up-regulates ECM synthesis and secretion. MCs transiently transfected with a plasmid overexpressing Egr1 expressed higher levels of fibronectin and type IV collagen and secreted more of these proteins in the culture medium than the control MCs. In cultures transfected with scrambled RNA, expression of fibronectin and type IV collagen was significantly higher under high-glucose conditions than under low-glucose conditions. We focused on fibronectin and type IV collagen because they are the major components of the ECM in the glomerular basement membrane. Transfecting cells with both M61-Egr1 and siEgr1 inhibited the up-regulation of fibronectin and type IV collagen.

TGF- $\beta$ contributes to MC proliferation, ECM synthesis, renal tubular damage, and renal interstitial fibrosis in diabetic nephropathy $[33,34]$. Studies have suggested that Egr1 regulates TGF- $\beta$ expression by binding to two GC-rich binding sites in the promoter [7]. At the same time, TGF- $\beta$ has been shown to induce Egr1 transcription through the classical Smad pathway in human skin fibroblasts [35]. We extend the literature by showing that, in the context of MCs under high-glucose conditions mimicking diabetic nephropathy, TGF- $\beta 1$ rapidly induces a short-term increase in the levels of Egr1 mRNA and protein, which is inhibited by TGF- $\beta 1$ inhibitor SB-431542. SB-431542 specifically inhibits the catalytic activity of the TGF- $\beta 1$ receptor, preventing the phosphorylation of Smad and thereby blocking the classic TGF- $\beta$ pathways [36]. At the same time, we show that Egr1 mediates high glucoseinduced TGF- $\beta 1$ up-regulation; treating cells with siEgr 1 inhibited this increase in TGF- $\beta 1$. Our ChIP results provide direct evidence that Egr1 binds to the TGF- $\beta 1$ promoter in MCs, and that high glucose promotes this binding.

While the present study extends the literature on Egr1 in contributing to diabetic nephropathy, it leaves many questions unanswered about how exactly the transcription factor transduces the effects of high glucose into ECM synthesis. Previous work suggests that mitogen-activated protein kinases (MAPKs) and protein kinase C (PKC) are upstream activators of Egr1. MAPK mediates Egr1 expression in response to growth factors and stress [37], while PKC up-regulates Egr1 in response to hypoxia, ischemia and atherosclerosis [9]. In glomerular endothelial cells, insulin and glucose can up-regulate the levels of Egr1 mRNA and protein [19], with insulin apparently acting through the extracellular signal-regulated kinase 1/2 (ERK1/2) signaling pathway, while glucose acts through the PKC pathway. These results suggest that the upstream regulators of Egr 1 may depend on cell type and conditions of stress or stimulation. Studies further suggest that the same stress or stimulation can stimulate multiple pathways that together regulate Egr1. Vascular endothelial growth factor 
(VEGF) can activate PKC and the MAPKs (ERK and P38) in endothelial cells, inducing the expression of Egr1, which in turn up-regulates tissue factor (TF) expression [38]. Indeed, the PKC and MAPK signaling pathways interact in regulating endothelial cell response to hypoxia [39]. The present study opens the door to investigating these complex questions of upstream regulation of Egr1 and its mechanism of action in diabetic nephropathy.

In summary, we combine in vitro and in vivo approaches to provide strong evidence that the transcription factor Egr1 promotes high glucose-induced MC proliferation and ECM synthesis and secretion. We further show that such effects involve a positive feedback loop of TGF- $\beta 1$. This work substantially expands our previous understanding of the role of Egr1 in diabetic nephropathy.

\section{Acknowledgments}

We thank Wenwei Xu and Lin Wang at the Department of Endocrinology and Metabolism at Nanfang Hospital at Southern Medical University (Guangzhou, China) for technical support. This work was supported, in part, by grants from the National Natural Science Foundation of China (31400992 and 81470047), the Special Project on Industrial Technology Research and Development of Guangdong (2010-207) and the Foundation of the President of Nanfang Hospital (2013B021).

\section{Disclosure Statement}

No potential conflicts of interest relevant to this article were reported.

\section{References}

1 Sukhatme VP, Cao XM, Chang LC, Tsai-Morris CH, Stamenkovich D, Ferreira PC, Cohen DR, Edwards SA, Shows TB, Curran T, et al.: A zinc finger-encoding gene coregulated with c-fos during growth and differentiation, and after cellular depolarization. Cell 1988;53:37-43.

2 Sukhatme VP: The egr transcription factor family: From signal transduction to kidney differentiation. Kidney Int 1992;41:550-553.

3 Friedrich B, Janessa A, Artunc F, Aicher WK, Muller GA, Lang F, Risler T, Alexander D: Doca and tgf-beta induce early growth response gene-1 (egr-1) expression. Cell Physiol Biochem 2008;22:465-474.

4 Ghosh AK, Murphy SB, Kishore R, Vaughan DE: Global gene expression profiling in pai-1 knockout murine heart and kidney: Molecular basis of cardiac-selective fibrosis. PloS One 2013;8:e63825.

5 Hofer G, Grimmer C, Sukhatme VP, Sterzel RB, Rupprecht HD: Transcription factor egr-1 regulates glomerular mesangial cell proliferation. J Biol Chem 1996;271:28306-28310.

6 Carl M, Akagi Y, Weidner S, Isaka Y, Imai E, Rupprecht HD: Specific inhibition of egr-1 prevents mesangial cell hypercellularity in experimental nephritis. Kidney Int 2003;63:1302-1312.

7 McCaffrey TA, Fu C, Du B, Eksinar S, Kent KC, Bush H Jr, Kreiger K, Rosengart T, Cybulsky MI, Silverman ES, Collins T: High-level expression of egr-1 and egr-1-inducible genes in mouse and human atherosclerosis. J Clin Invest 2000;105:653-662.

8 Nakamura H, Isaka Y, Tsujie M, Rupprecht HD, Akagi Y, Ueda N, Imai E, Hori M: Introduction of DNA enzyme for egr-1 into tubulointerstitial fibroblasts by electroporation reduced interstitial alpha-smooth muscle actin expression and fibrosis in unilateral ureteral obstruction (uuo) rats. Gene Ther 2002;9:495-502.

9 Yan SF, Harja E, Andrassy M, Fujita T, Schmidt AM: Protein kinase c beta/early growth response-1 pathway: A key player in ischemia, atherosclerosis, and restenosis. J Am Coll Cardiol 2006;48:A47-55.

10 Gil N, Goldberg R, Neuman T, Garsen M, Zcharia E, Rubinstein AM, van Kuppevelt T, Meirovitz A, Pisano C, Li JP, van der Vlag J, Vlodavsky I, Elkin M: Heparanase is essential for the development of diabetic nephropathy in mice. Diabetes 2012;61:208-216. 


\section{Cellular Physiology Cell Physiol Biochem 2015;36:2093-2107 \begin{tabular}{l|l|l}
\hline DOI: 10.1159/000430177 & (C) 2015 S. Karger AG, Basel
\end{tabular}

11 Zhang Y, Li H, Hao J, Zhou Y, Liu W: High glucose increases cdk5 activity in podocytes via transforming growth factor-beta1 signaling pathway. Exp Cell Res 2014;326:219-229.

12 Zhu B, Li CZ, Qian Y, Pan YH, Zhang Y, Xue YM: Relationship between visceral fat depot and adiponectin mRNA level in the adipose tissue of oletf rats. Nan Fang Yi Ke Da Xue Xue Bao 2011;31:1341-1344.

13 Li J, Guan M, Li C, Lyv F, Zeng Y, Zheng Z, Wang C, Xue Y: The dipeptidyl peptidase-4 inhibitor sitagliptin protects against dyslipidemia-related kidney injury in apolipoprotein e knockout mice. Int J Mol Sci 2014;15:11416-11434.

14 Zeng Y, Li C, Guan M, Zheng Z, Li J, Xu W, Wang L, He F, Xue Y: The dpp-4 inhibitor sitagliptin attenuates the progress of atherosclerosis in apolipoprotein-e-knockout mice via ampk- and mapk-dependent mechanisms. Cardiovasc Diabetol 2014;13:32.

15 Svaren J, Ehrig T, Abdulkadir SA, Ehrengruber MU, Watson MA, Milbrandt J: Egr1 target genes in prostate carcinoma cells identified by microarray analysis. J Biol Chem 2000;275:38524-38531.

16 Abboud HE: Mesangial cell biology. Exp Cell Res 2012;318:979-985.

17 Cohen MP, Lautenslager GT, Shearman CW: Increased collagen iv excretion in diabetes. A marker of compromised filtration function. Diabetes Care 2001;24:914-918.

18 Xu WW, Guan MP, Zheng ZJ, Gao F, Zeng YM, Qin Y, Xue YM: Exendin-4 alleviates high glucose-induced rat mesangial cell dysfunction through the ampk pathway. Cell Physiol Biochem 2014;33:423-432.

19 Hasan RN, Phukan S, Harada S: Differential regulation of early growth response gene-1 expression by insulin and glucose in vascular endothelial cells. Arterioscler Thromb Vasc Biol 2003;23:988-993.

20 Josefsen K, Sorensen LR, Buschard K, Birkenbach M: Glucose induces early growth response gene (egr-1) expression in pancreatic beta cells. Diabetologia 1999;42:195-203.

21 Vedantham S, Thiagarajan D, Ananthakrishnan R, Wang L, Rosario R, Zou YS, Goldberg I, Yan SF, Schmidt AM, Ramasamy R: Aldose reductase drives hyperacetylation of egr-1 in hyperglycemia and consequent upregulation of proinflammatory and prothrombotic signals. Diabetes 2014;63:761-774.

22 Han DC, Isono M, Hoffman BB, Ziyadeh FN: High glucose stimulates proliferation and collagen type i synthesis in renal cortical fibroblasts: Mediation by autocrine activation of tgf-beta. J Am Soc Nephrol 1999;10:1891-1899.

23 Cove-Smith A, Hendry BM: The regulation of mesangial cell proliferation. Nephron Exp Nephrol 2008;108:e74-79.

24 Solow BT, Derrien A, Smith JA, Jarett L, Harada S: Angiotensin ii inhibits insulin-induced egr-1 expression in mesangial cells. Arch Biochem Biophys 1999;370:308-313.

25 Mechtcheriakova D, Wlachos A, Holzmuller H, Binder BR, Hofer E: Vascular endothelial cell growth factorinduced tissue factor expression in endothelial cells is mediated by egr-1. Blood 1999;93:3811-3823.

26 Fang M, Wee SA, Ronski K, Fan H, Tao S, Lin Q: Evidence of egr1 as a differentially expressed gene among proliferative skin diseases. Genomic Med 2007;1:75-85.

27 de Belle I, Huang RP, Fan Y, Liu C, Mercola D, Adamson ED: P53 and egr-1 additively suppress transformed growth in ht1080 cells but egr-1 counteracts p53-dependent apoptosis. Oncogene 1999;18:3633-3642.

28 Virolle T, Adamson ED, Baron V, Birle D, Mercola D, Mustelin T, de Belle I: The egr-1 transcription factor directly activates pten during irradiation-induced signalling. Nat Cell Biol 2001;3:1124-1128.

29 Ham J, Eilers A, Whitfield J, Neame SJ, Shah B: C-jun and the transcriptional control of neuronal apoptosis. Biochem Pharmacol 2000;60:1015-1021.

30 Haas TL, Stitelman D, Davis SJ, Apte SS, Madri JA: Egr-1 mediates extracellular matrix-driven transcription of membrane type 1 matrix metalloproteinase in endothelium. J Biol Chem 1999;274:22679-22685.

31 Liu C, Yao J, Mercola D, Adamson E: The transcription factor egr-1 directly transactivates the fibronectin gene and enhances attachment of human glioblastoma cell line u251. J Biol Chem 2000;275:20315-20323.

32 Bryant M, Drew GM, Houston P, Hissey P, Campbell CJ, Braddock M: Tissue repair with a therapeutic transcription factor. Hum Gene Ther 2000;11:2143-2158.

33 Ziyadeh FN: Mediators of diabetic renal disease: The case for tgf-beta as the major mediator. J Am Soc Nephrol 2004;15:S55-57.

34 Lu A, Miao M, Schoeb TR, Agarwal A, Murphy-Ullrich JE: Blockade of tsp1-dependent tgf-beta activity reduces renal injury and proteinuria in a murine model of diabetic nephropathy. Am J pathol 2011;178:2573-2586. 


\section{Cellular Physiology Cell Physiol Biochem 2015;36:2093-2107}

and Biochemistry

35 Chen SJ, Ning H, Ishida W, Sodin-Semrl S, Takagawa S, Mori Y, Varga J: The early-immediate gene egr-1 is induced by transforming growth factor-beta and mediates stimulation of collagen gene expression. J Biol Chem 2006;281:21183-21197.

36 Laping NJ, Grygielko E, Mathur A, Butter S, Bomberger J, Tweed C, Martin W, Fornwald J, Lehr R, Harling J, Gaster L, Callahan JF, Olson BA: Inhibition of transforming growth factor (tgf)-beta1-induced extracellular matrix with a novel inhibitor of the tgf-beta type i receptor kinase activity: Sb-431542. Mol Pharmacol 2002;62:58-64.

37 Gitenay D, Baron VT: Is egr1 a potential target for prostate cancer therapy? Future Oncol 2009;5:993-1003.

38 Mechtcheriakova D, Schabbauer G, Lucerna M, Clauss M, De Martin R, Binder BR, Hofer E: Specificity, diversity, and convergence in vegf and tnf-alpha signaling events leading to tissue factor up-regulation via egr-1 in endothelial cells. FASEB J 2001;15:230-242.

39 Lo LW, Cheng JJ, Chiu JJ, Wung BS, Liu YC, Wang DL: Endothelial exposure to hypoxia induces egr-1 expression involving pkcalpha-mediated ras/raf-1/erk1/2 pathway. J Cell physiol 2001;188:304-312. 